\title{
Research on the Optimal Reactive Power Control of the Wind Farm by Flow Calculation
}

\author{
Zhuofan Tang1, a, Lijun Qin ${ }^{1, b}$, Xian Wang ${ }^{1, c}$ and Jun Liang ${ }^{2, d}$ \\ ${ }^{1}$ School of Electrical and Electronic Engineering, North China Electric Power University, Beijing \\ 102206, China; \\ 2Bazhou Power Supply Company, State Grid Corporation of China, Xinjiang 841000, China. \\ atangvera@126.com, bqinlj@126.com, cstillalice10@163.com, d820515425@qq.com
}

\begin{abstract}
Keywords: Wind turbine generation system, flow calculation, reactive power optimization control, and PSASP simulation.
\end{abstract}

\begin{abstract}
Wind energy is clean and renewable, with the progress of the wind power technology, the accumulation of operation and maintenance experience, reduced generation cost, large capacity of wind farms connected to grid have been built. It is urgent to study the reactive power optimization control of the wind farm, so as to realize the wind farm and power system stability, reliable, good and economic operation. This paper established a wind farm containing 33 sets of $1.5 \mathrm{MW}$ double-fed wind turbines in power system analysis software package (PSASP). Through the 18 kinds of different operating types of the power flow calculation by PSASP simulation, the optimal reactive power control scheme is presented by comprehensive analysis on power flow calculation results to finish the wind farm reactive power optimization control aim. Accordingly, this paper makes a detailed analysis of the reactive power optimization control scheme, such as the choice of the compensation device, the position of the compensation and the compensation capacity, by comparing the power flow calculation results before and after the installation of reactive power compensation equipment in the wind farm, the effectiveness of the reactive power optimized control scheme is verified.
\end{abstract}

\section{Introduction}

Wind energy is clean and renewable. Due to the randomness of the wind, the wind farm when connected to the network has a great impact on the power system. And the power flow calculation is the main way to carry out quantitative analysis of the impact [1-3].

The larger size of the wind farm, the difference between the output powers of each wind turbine will be more apparent, and the internal loss of the wind farm collector lines will be greater. It is possible to detect the power, voltage and current by the flow calculation of the wind farm which is running. Then we can determine whether the various equipment or the node within the wind farm is abnormal. If there is an abnormal situation, we can quickly take the appropriate solution to optimize the power control of the wind farm and solve problems. For wind farms are in the planning stage, we can provide the reasonable running option, the correct choice of electrical primary and secondary equipment by flow calculation. For the wind farm running in the primary stage, the reactive power optimization is not perfect, resulting in a series of problems. Through the power flow calculation, we can take the power optimization control of the wind farm to reduce the power loss, so that the wind farm and the whole network will be in reliable, good, economical operation [4-6].

This paper established a wind farm containing 33 sets of $1.5 \mathrm{MW}$ double-fed wind turbines in power system analysis software package (PSASP). Through the 18 kinds of different operating types of the power flow calculation by PSASP simulation, the optimal reactive power control scheme is presented by comprehensive analysis on power flow calculation results to finish the wind farm reactive power optimization control aim. Accordingly, this paper makes a detailed analysis of the reactive power optimization control scheme, such as the choice of the compensation device, the position of the compensation and the compensation capacity, by comparing the power flow calculation results before 
and after the installation of reactive power compensation equipment in the wind farm, the effectiveness of the reactive power optimized control scheme is verified.

\section{The Reactive Power Control of the Wind Farm}

For the reactive power optimization control of power systems with wind farms, the wind farm needs to provide the prediction information data of the wind and the ability of reactive power adjustment and other data as much as possible. For the reactive power optimization control inside the wind farm, the power grid needs to release a variety of control indicators to the wind farm. The two are interrelated and inseparable [7].

Using the reactive power compensation in the wind farm can reduce the power loss of the collector line and improve the stable operation characteristics of the whole power grid. And the power quality problem of the wind farm can be solved in different degree. The main role is the control of the voltage, in particular, it can suppress the wind farm voltage fluctuations to maintain the voltage level of the main bus in wind farm and the grid for improving the operation condition of the entire grid $[8,9]$.

The reactive power compensation devices based on FACTS technology are static var compensator (SVC) and static synchronous compensator (STATCOM). And SVC is divided into TCR (thyristor controlled reactor) type and MCR (magnetically controlled reactor) type. Both of them can achieve continuous adjustment of reactive power, but the reflecting speed of the MCR-type SVC is relatively slow, so there may be some risk when running. The adjustment speed of the TCR-type SVC is fast, the voltage control and reactive power control can be taken at the same time. STATCOM is an ideal reactive power compensation device, because the use of thyristor, it is not cheap.

\section{Flow Calculation and Results Analysis of the Wind Farm}

\subsection{The Basic Situation of the Wind Farm.}

The geographical wiring diagram of the wind farm is shown in Fig1.The scale of the wind farm is 50MW, and 33 sets of GE1.5MW double-fed wind turbines are installed. The diameter of the wind wheel is $77 \mathrm{~m}$ and the hub height is $64.7 \mathrm{~m}$. Because of the flat location of the wind farm, the wind turbine is $600 \mathrm{~m}$ in the wind direction and $500 \mathrm{~m}$ in the vertical direction of the wind direction. Arrangement direction of the wind turbines is perpendicular to the dominant wind direction, and both rows are staggered as far as possible. So the line spacing is set to 6 times the diameter of the wind wheel, the column spacing is set to 4 times the diameter of the wind wheel [10].

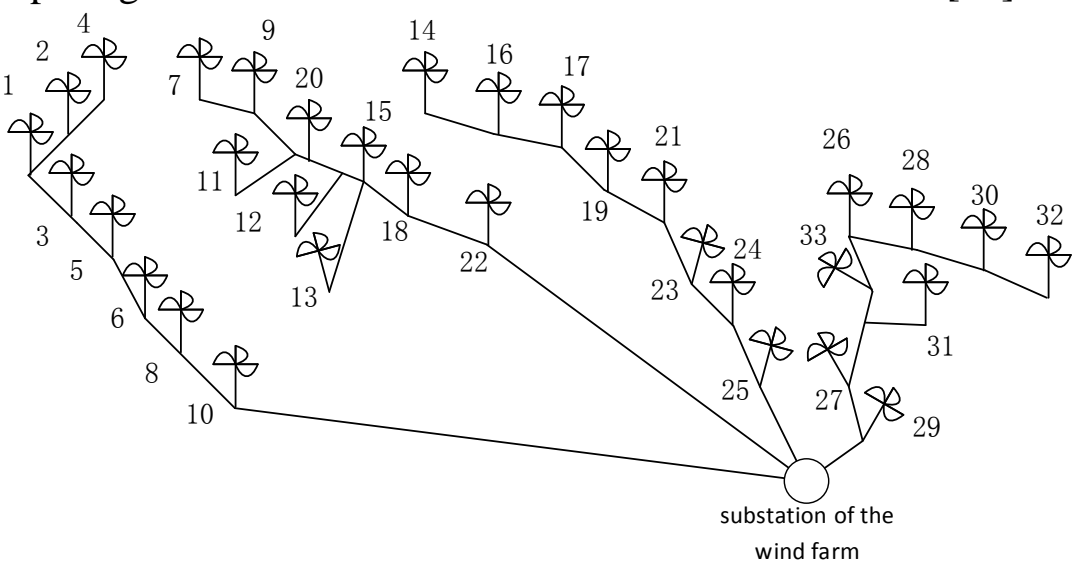

Fig. 1 The geographical wiring diagram of the wind farm

There is a $220 \mathrm{KV}$ step-up substation in the wind farm. The step-up substation adopts single bus connection. The output voltage of the double-fed wind turbine is $0.69 \mathrm{KV}$. It is connected to the low voltage side of the box transformer via a low voltage cable. In order to reduce line losses, box-type transformers are located near the unit. The classic "one machine a change" unit wiring is used between the double-fed unit and box-type transformer. The capacity of each box-type transformer is 1600KVA, and the high-voltage side of the box-type transformer takes a parallel connection. 
For the low voltage side of the main transformer, it is essential to shorten the length of the line according to geographical conditions as far as possible. So the 33 sets of double-fed units are divided into four groups to the collector system, and then collected to the step-up substation of the wind farm. All overhead lines are the LGJ-185 overhead line [11, 12].

\subsection{Flow Calculation of the Wind Farm.}

The wind farm is controlled by constant power factor, and the wind turbine is equivalent to the PQ node. Therefore, use the standard system to calculate the power flow by PSASP. The power factor is 1.0 , the reference capacity $S_{B}$ is $10 \mathrm{MVA}$, the reference voltage $U_{B}$ is equal to rated voltage $U_{N}$. Bus1 is the transformer inlet (low side) bus node of the wind farm step-up substation. Bus2 is the transformer outlet (high side) bus node (connected to the grid) of the wind farm step-up substation. Generation4 is the wind turbine transformer inlet (low side) node farthest from the wind farm substation.

According to the system operation mode, the power output of the wind farm and the position of the main transformer tap, the power flow calculation of 18 different ways is carried out respectively. The results are shown in Table 1 and Table 2.

Table 1 Calculation results of critical node voltage of wind farm

\begin{tabular}{|c|c|c|c|c|c|c|}
\hline \multicolumn{4}{|c|}{ Flow calculation settings } & \multicolumn{3}{|c|}{ Critical node voltage } \\
\hline $\begin{array}{c}\text { System } \\
\text { operation mode }\end{array}$ & $\begin{array}{l}\text { Power output of } \\
\text { the wind farm }\end{array}$ & $\begin{array}{l}\text { Position of the main } \\
\text { transformer tap }\end{array}$ & Numble & $\begin{array}{c}\text { Bus2 } \\
(220 \mathrm{KV})\end{array}$ & $\begin{array}{c}\text { Bus1 } \\
(35 \mathrm{KV})\end{array}$ & $\begin{array}{c}\text { Generation } 4 \\
(0.69 \mathrm{KV})\end{array}$ \\
\hline \multirow{9}{*}{$\begin{array}{c}\text { Maximum } \\
\text { operation mode } \\
U=1.07\end{array}$} & \multirow{3}{*}{ Maximum } & Highest & 1 & 1.065890 & 0.964570 & 0.935564 \\
\hline & & Main taps & 2 & 1.066538 & 1.064550 & 1.035626 \\
\hline & & Lowest & 3 & 1.067315 & 1.175036 & 1.138892 \\
\hline & \multirow{3}{*}{ Minimum } & Highest & 4 & 1.070824 & 0.995230 & 0.938776 \\
\hline & & Main taps & 5 & 1.071125 & 1.078650 & 1.035885 \\
\hline & & Lowest & 6 & 1.071435 & 1.223190 & 1.143056 \\
\hline & \multirow{3}{*}{$50 \%$ rated power } & Highest & 7 & 1.068599 & 0.985563 & 0.944815 \\
\hline & & Main taps & 8 & 1.069642 & 1.073296 & 1.031224 \\
\hline & & Lowest & 9 & 1.071344 & 1.197235 & 1.124965 \\
\hline \multirow{9}{*}{$\begin{array}{c}\text { Minimum } \\
\text { operation mode } \\
\mathrm{U}=0.97\end{array}$} & \multirow{3}{*}{ Maximum } & Highest & 10 & 0.954934 & 0.779683 & 0.764553 \\
\hline & & Main taps & 11 & 0.958702 & 0.852180 & 0.847967 \\
\hline & & Lowest & 12 & 0.959344 & 0.984254 & 0.963665 \\
\hline & \multirow{3}{*}{ Minimum } & Highest & 13 & 0.970615 & 0.893556 & 0.851276 \\
\hline & & Main taps & 14 & 0.970864 & 0.975540 & 0.925645 \\
\hline & & Lowest & 15 & 0.972363 & 1.087765 & 1.034349 \\
\hline & \multirow{3}{*}{$50 \%$ rated power } & Highest & 16 & 0.971158 & 0.893564 & 0.851386 \\
\hline & & Main taps & 17 & 0.971269 & 0.986885 & 0.942010 \\
\hline & & Lowest & 18 & 0.971343 & 1.101536 & 1.039629 \\
\hline
\end{tabular}

\subsection{Results Analysis of the Flow Calculation.}

(1) The mainly active power loss of the wind farm is the box-type transformer active power loss.

As the length of the four groups of collector lines are $3.5 \mathrm{~km}, 1.5 \mathrm{~km}, 1.5 \mathrm{~km}, 0.8 \mathrm{~km}$, the impedance of the line is small. So the active power loss of the transmission line is not about one third of the active power loss of the main transformer. But the power loss of the main transformer is about $20 \%$ of the total loss.

(2) The higher the system voltage level, the smaller the reactive power that needs to be absorbed from the system.

When the system voltage level is the highest, the need to inject the reactive power is 7 to $10 \mathrm{Mvar}$ or so, when the system voltage level is the lowest, the need to inject the reactive power is 21 to $25 \mathrm{Mvar}$ or so. Therefore, the higher the voltage level of the system, the more favorable operation of the wind farm. 
Table 2 Calculation results of key branch power and power loss of wind farm

\begin{tabular}{|c|c|c|c|c|c|}
\hline \multirow{2}{*}{ Numble } & \multicolumn{2}{|c|}{ Key branch power } & \multicolumn{2}{|c|}{ Power loss } & \multirow{2}{*}{ Total loss } \\
\hline & Bus2 & Bus1 & Main transformer & Line & \\
\hline \multirow{2}{*}{1} & 0.4890225 & 0.4917955 & 0.002206153 & 0.001497162 & 0.011024 \\
\hline & $-\mathrm{j} 0.1003023$ & $-\mathrm{j} 0.02593783$ & $+\mathrm{j} 0.067362953$ & +j0.008992 & \\
\hline \multirow{2}{*}{2} & 0.490331667 & 0.493094333 & 0.002196045 & 0.001489633 & 0.009708 \\
\hline & $-\mathrm{j} 0.0883437$ & -j0.01428967 & $+\mathrm{j} 0.067054322$ & +j0.008919 & \\
\hline \multirow{2}{*}{3} & 0.491511667 & 0.4942645 & 0.002186155 & 0.001488767 & 0.00852 \\
\hline & -j0.0755312 & -j0.00177783 & +j0.066752307 & +j0.008848 & \\
\hline \multirow{2}{*}{4} & 0.001529667 & 0.0018165 & 3.59833E-06 & $1.03833 \mathrm{E}-06$ & $4.85 \mathrm{E}-06$ \\
\hline & $+\mathrm{j} 0.01066783$ & $+\mathrm{j} 0.0142765$ & +j0.000109842 & $+\mathrm{j} 0.00483$ & \\
\hline \multirow{2}{*}{5} & 0.001526833 & 0.001816333 & 0.00000628 & $1.88833 \mathrm{E}-06$ & 8.34E-06 \\
\hline & +j0.015289 & $+\mathrm{j} 0.0189795$ & +j0.000191738 & $+\mathrm{j} 0.004823$ & \\
\hline \multirow{2}{*}{6} & 0.001522 & 0.018164667 & $1.10083 \mathrm{E}-05$ & $3.41167 \mathrm{E}-06$ & $1.46 \mathrm{E}-05$ \\
\hline & $+\mathrm{j} 0.02143333$ & $+\mathrm{j} 0.002527033$ & $+\mathrm{j} 0.000336128$ & $+\mathrm{j} 0.004811$ & \\
\hline \multirow{2}{*}{7} & 0.245658167 & 0.2473115 & 0.001086598 & 0.000368267 & 0.00326 \\
\hline & $-\mathrm{j} 0.0359825$ & $+\mathrm{j} 0.0041965$ & $+\mathrm{j} 0.024785428$ & $+\mathrm{j} 0.001435$ & \\
\hline \multirow{2}{*}{8} & 0.245983667 & 0.247633 & 0.001082812 & 0.000366628 & 0.002933 \\
\hline & $-\mathrm{j} 0.0295645$ & $+\mathrm{j} 0.010495833$ & +j0.012071082 & $+\mathrm{j} 0.001452$ & \\
\hline \multirow{2}{*}{9} & 0.246277833 & 0.247923667 & 0.001079213 & 0.000364972 & 0.002637 \\
\hline & $-\mathrm{j} 0.0216345$ & $+\mathrm{j} 0.018318333$ & +j0.001079213 & $+\mathrm{j} 0.00147$ & \\
\hline \multirow{2}{*}{10} & 0.4811935 & 0.488289 & 0.00652895 & 0.002227662 & 0.019584 \\
\hline & $-\mathrm{j} 0.257942$ & $-\mathrm{j} 0.0515865$ & +j0.199355763 & +j0.016637 & \\
\hline \multirow{2}{*}{11} & 0.483513167 & 0.490421167 & 0.006341398 & 0.002162465 & 0.017199 \\
\hline & $-\mathrm{j} 0.2374157$ & $-\mathrm{j} 0.03678733$ & +j0.193629065 & $+\mathrm{j} 0.01603$ & \\
\hline \multirow{2}{*}{12} & 0.485532167 & 0.4922585 & 0.006174627 & 0.002104385 & 0.015137 \\
\hline & $-\mathrm{j} 0.2176435$ & $-\mathrm{j} 0.02210733$ & +j0.188536825 & +j0.015489 & \\
\hline \multirow{2}{*}{13} & 0.001530667 & 0.001816333 & 0.00000233 & 5.73333E-07 & $3.16 \mathrm{E}-06$ \\
\hline & $+\mathrm{j} 0.00675817$ & $+\mathrm{j} 0.010329167$ & $+\mathrm{j} 0.000071135$ & +j0.003971 & \\
\hline \multirow{2}{*}{14} & 0.001529 & 0.0018165 & $4.35833 \mathrm{E}-06$ & $1.17667 \mathrm{E}-06$ & $5.75 \mathrm{E}-06$ \\
\hline & $+\mathrm{j} 0.01063867$ & $+\mathrm{j} 0.0142705$ & $+\mathrm{j} 0.000133073$ & $+\mathrm{j} 0.003967$ & \\
\hline \multirow{2}{*}{15} & 0.001525 & 0.001816333 & $8.00667 \mathrm{E}-06$ & $2.30167 \mathrm{E}-06$ & $1.05 \mathrm{E}-05$ \\
\hline & $+\mathrm{j} 0.01573917$ & $+\mathrm{j} 0.019483833$ & $+\mathrm{j} 0.000244465$ & $+\mathrm{j} 0.003958$ & \\
\hline \multirow{2}{*}{16} & 0.023797167 & 0.024094833 & $1.45083 \mathrm{E}-05$ & 4.61833E-06 & $4.09 \mathrm{E}-05$ \\
\hline & $+\mathrm{j} 0.00630817$ & $+\mathrm{j} 0.010250833$ & $+\mathrm{j} 0.000442975$ & +j0.003934 & \\
\hline \multirow{2}{*}{17} & 0.023799 & 0.024098833 & $1.64333 \mathrm{E}-05$ & $5.18667 \mathrm{E}-06$ & $3.95 \mathrm{E}-05$ \\
\hline & $+\mathrm{j} 0.01014583$ & $+\mathrm{j} 0.0141475$ & $+\mathrm{j} 0.000501755$ & +j0.00393 & \\
\hline \multirow{2}{*}{18} & 0.023798833 & 0.024102667 & 0.000020165 & 0.000006335 & $4.09 \mathrm{E}-05$ \\
\hline & $+\mathrm{i} 0.01549667$ & $+\mathrm{j} 0.019612667$ & $+\mathrm{j} 0.000615712$ & $+\mathrm{i} 0.003921$ & \\
\hline
\end{tabular}

(3) The lower the tap position of the main transformer, the more favorable the distribution of the reactive power flow in the wind farm.

In general, the lower the position of the main transformer tap, the smaller the actual ratio of the transformer. When maintaining the system voltage level, it is more conducive to improve the $35 \mathrm{KV}$ operating voltage level of the wind farm. The $35 \mathrm{KV}$ network of the wind farm contains a large number of confluent bus lines, and its charging power is proportional to the square of the operating voltage. As a result, the operating voltage level of the $35 \mathrm{KV}$ network of the wind farm will increase with the decrease of the main transformer tap position, and the charging power of the collector circuit will be higher. It is necessary to pay attention to the range of the Bus1 voltage allowable value by adjusting the main transformer tap position to maintain the $35 \mathrm{KV}$ network operating voltage level. During normal operation, the Bus1 has a voltage limit of $-3 \%$ to $+7 \%$ of the rated voltage. After a fault, the Bus1 has a voltage limit of $-10 \%$ to $+10 \%$ of the rated voltage.

(4) When the system voltage level is the highest, the wind farm needs to install the reactive power compensation device to solve the Bus2 high voltage level. 
Operating in the maximum mode of the system, only the power output of the wind farm is the largest that is close to the rated power, the Bus2 voltage level of the wind farm can be controlled within the range permitted by normal operation. When the power output of the wind farm is the smallest, the Bus2 voltage level of the wind farm can't be controlled within the range of normal operation, regardless of how to adjust the main transformer tap position. When the output power of the wind farm is half of the rated power, the Bus2 voltage level of the wind farm can't be controlled within the range of normal operation as the main transformer tap position is the lowest. In addition, in some operating mode, the Bus1 voltage level can't be controlled within the allowable voltage deviation range. So the wind farm needs to install the reactive power compensation device to solve the Bus2 high voltage level.

(5) When the system voltage level is the lowest, it is necessary to adjust the main transformer tap position to solve the problem of low voltage level of Bus1.

When the system voltage level is the lowest, the Bus1 voltage level in different operation modes is low. However, in the case of the same output power of the wind farm, the operating voltage can be found to meet the normal operation requirements by adjusting the main transformer tap position. And the system voltage is relatively low, it shows that the system needs more reactive power or the system has a fault. In this case, the system needs to receive reactive power support, but the wind farm in these nine modes of operation, at least needs to absorb 21.76Mvar from the system reactive power, up to the system into the $1.55 \mathrm{Mvar}$ reactive power, which will have an adverse effect on the operation of the power system.

The main tasks of the power optimization control of the wind farm are as follows: make full use of the existing wind resources and improve the utilization rate of wind energy as much as possible, install the reactive power compensation device to solve the problem that Bus2 voltage level is high as the system voltage level is high.

\section{Design of the Reactive Power Optimization Control of the Wind Farm}

\subsection{Detailed Design.}

When the system voltage level is higher, the Bus2 voltage is high. We can see from the four kinds operation of power flow calculation such as 4,5,6,9. The operation4, operation5 and operation6, show that the reactive power injected into the wind farm are1.07Mvar, 1.53Mvar, 2.14Mvar. And the operation9 show that the reactive power absorbed from the system into the wind farm is $2.16 \mathrm{Mvar}$. Therefore, the design of the reactive power optimization control of the wind farm should use the reactive power compensation device that can both send and absorb the reactive power.

When the system voltage level is low, the Bus1 voltage is low. We can see from the four kinds operation of power flow calculation such as $10,11,13,16$. And the operation 11 is running on the main tap position, and the other three operations are located on the highest tap position. Therefore, by properly lowering the main transformer tap position, it is possible to properly handle the problem of Bus1low voltage. The results of the operation12, 14,15,17,18 show the rationality and correctness of this method.

Based on the main tasks of the power optimization control of the wind farm, select the TCR-type SVC as the reactive power compensation equipment of the wind farm, which can both send and absorb the reactive power. And it can be continuous smooth adjusted with experienced equipment manufacturing and operation. Also the price is reasonable.

From the operation1, 2, 3, 10,11, 12 results show that when the power output of the wind farm is relatively large, it needs the grid supply reactive power to $35 \mathrm{KV}$ network through the main transformer, so as to supply reactive power to the box transformer. In other modes of operation, if the grid injects reactive power into the wind field, the injected reactive power becomes part of the reactive power required for the main transformer, and the other part of the reactive power required for the main transformer needs from the collector line. That can be verified from operation7, 8, and 9. 
Therefore, the focus of the wind field compensation is the main transformer. And centralized compensation solution of reactive power compensation is used. The location of the compensation is in Bus1 on the low voltage side of the main transformer. Thus to supplying reactive power to the main transformer, while the power output of the wind farm is relatively large, it can also supply reactive power to box transformer.

When the system voltage level is higher, the Bus2 voltage is high. We can see from the four kinds operation of power flow calculation such as 4,5,6,9. Therefore, it is necessary to set the Bus1 as a PV node, set the appropriate voltage level according to the result of the operation, and then calculate the power flow again. If the result of the power flow calculation shows that the Bus2 voltage level still does not meet the requirements, reset the PV node voltage and repeat the power flow calculation until the Bus2 voltage level meets the requirements. So that the reactive power of the PV node is the compensation power of the reactive power compensation device. Considering a certain margin and the serialization of reactive power compensation device, the capacity of reactive power compensation equipment of the wind farm is obtained [13]. Calculation results of determining the reactive power compensation is shown in Table 3.

Table 3 Calculation results of determining the reactive power compensation

\begin{tabular}{|c|c|c|c|c|c|c|}
\hline $\begin{array}{l}\text { System } \\
\text { operation } \\
\text { mode }\end{array}$ & $\begin{array}{l}\text { Power output } \\
\text { of the wind } \\
\text { farm }\end{array}$ & $\begin{array}{l}\text { Position of the } \\
\text { main } \\
\text { transformer } \\
\text { tap }\end{array}$ & Number & $\begin{array}{l}\text { Bus2 node } \\
\text { voltage }\end{array}$ & $\begin{array}{l}\text { Bus1 node } \\
\text { voltage }\end{array}$ & $\begin{array}{c}\text { Compensation } \\
\text { power }\end{array}$ \\
\hline \multirow{4}{*}{$\begin{array}{c}\text { Maximum } \\
\text { operation } \\
\text { mode } \\
\mathrm{U}=1.07\end{array}$} & \multirow{3}{*}{ Minimum } & Highest & $19(4+S V C)$ & 1.069322 & 0.97 & -0.025620 \\
\hline & & Main taps & $20(5+$ SVC $)$ & 1.069447 & 1.07 & -0.025233 \\
\hline & & Lowest & $21(6+S V C)$ & 1.059726 & 1.07 & -0.174947 \\
\hline & $\begin{array}{c}50 \% \text { rated } \\
\text { power }\end{array}$ & Lowest & $22(9+\mathrm{SVC})$ & 1.058357 & 1.07 & -0.154877 \\
\hline
\end{tabular}

4.2 Analysis on Operation Effect of the Wind Farm after Installing Reactive Power Compensation Device.

(1) The operation of the wind farm has been improved.

After installing the reactive power compensation device, the new power flow calculation data of these operation modes are shown in Table 4.

Table 4 Comparison of flow calculation results before and after adding reactive power compensator

\begin{tabular}{|c|c|c|c|c|c|}
\hline $\begin{array}{c}\text { System } \\
\text { operation mode }\end{array}$ & $\begin{array}{l}\text { Power output of } \\
\text { the wind farm }\end{array}$ & $\begin{array}{l}\text { Position of the main } \\
\text { transformer tap }\end{array}$ & Number & $\begin{array}{l}\text { Bus2 node } \\
\text { voltage }\end{array}$ & $\begin{array}{l}\text { Bus1 node } \\
\text { voltage }\end{array}$ \\
\hline \multirow{6}{*}{$\begin{array}{c}\text { Maximum } \\
\text { operation mode } \\
U=1.07\end{array}$} & \multirow{4}{*}{ Maximum } & \multirow{2}{*}{ Highest } & 1 & 1.065890 & 0.964570 \\
\hline & & & $23(1+\mathrm{SVC})$ & 1.070154 & 0.996 \\
\hline & & \multirow{2}{*}{ Lowest } & 3 & 1.067315 & 1.175036 \\
\hline & & & $24(3+\mathrm{SVC})$ & 1.063272 & 1.145 \\
\hline & \multirow{2}{*}{$50 \%$ rated power } & \multirow{2}{*}{ Main taps } & 8 & 1.069642 & 1.073296 \\
\hline & & & $25(8+S V C)$ & 1.023576 & 1.015 \\
\hline \multirow{8}{*}{$\begin{array}{c}\text { Minimum } \\
\text { operation mode } \\
U=0.97\end{array}$} & \multirow{4}{*}{ Maximum } & \multirow{2}{*}{ Highest } & 10 & 0.954934 & 0.779683 \\
\hline & & & $26(10+$ SVC $)$ & 0.998248 & 0.825 \\
\hline & & \multirow{2}{*}{ Main taps } & 11 & 0.958702 & 0.852180 \\
\hline & & & $27(11+$ SVC $)$ & 0.967768 & 0.975 \\
\hline & \multirow{2}{*}{ Minimum } & \multirow{2}{*}{ Highest } & 13 & 0.970615 & 0.893556 \\
\hline & & & $28(13+\mathrm{SVC})$ & 0.976837 & 0.955 \\
\hline & \multirow{2}{*}{$50 \%$ rated power } & \multirow{2}{*}{ Highest } & 16 & 0.971158 & 0.893564 \\
\hline & & & $29(16+\mathrm{SVC})$ & 0.976557 & 0.965 \\
\hline
\end{tabular}

Analyzing Table 4, you can get: after installing reactive power compensation equipment, the wind farm operating conditions have been improved. For example, compared to operation 8 , the voltage level of Bus1 in operation 25 is controlled from 1.073296 to 1.015.

(2) The power loss of the wind farm is reduced obviously. 
When the system voltage level is low and the wind farm power output is relatively large, the wind farm active power loss is the largest. The active power loss of the operation10, 11, 12 are 1.9584MW, 1.7199MW, 1.5137MW. However, in these three operations, only the voltage level of the Bus1 in operation 12 is maintained within the normal range.

After installing the reactive power compensation equipment to Bus1, the voltage level of Bus1 is further improved. The output power of the reactive power compensation device SVC is $15.8 \mathrm{Mvar}$, the total active loss of the wind farm is reduced from 1.5137MW to $1.3024 \mathrm{MW}$.

\section{Summary}

This paper established a wind farm containing 33 sets of $1.5 \mathrm{MW}$ double-fed wind turbines in power system analysis software package (PSASP). After 18 kinds of different operating types of the power flow calculation by PSASP simulation, this paper makes a detailed analysis of the results. The mainly active power loss of the wind farm is the box-type transformer active power loss. The higher the system voltage level, the smaller the reactive power that needs to be absorbed from the system. The lower the tap position of the main transformer, the more favorable the distribution of the reactive power flow in the wind farm. When the system voltage level is the highest, the wind farm needs to install the reactive power compensation device to solve the Bus2 high voltage level. When the system voltage level is the lowest, it is necessary to adjust the main transformer tap position to solve the problem of low voltage level of Bus1.

The main tasks of the power optimization control of the wind farm are as follows: make full use of the existing wind resources and improve the utilization rate of wind energy as much as possible, install the reactive power compensation device to solve the problem that Bus2 voltage level is high as the system voltage level is high.

Accordingly, this paper makes a detailed analysis of the reactive power optimization control scheme, such as the choice of the compensation device, the position of the compensation and the compensation capacity, by comparing the power flow calculation results before and after the installation of reactive power compensation equipment in the wind farm, the operation of the wind farm has been improved, the power loss of the wind farm is reduced obviously. So the effectiveness of the reactive power optimized control scheme is verified.

\section{References}

[1]. SUN Guoqiang, LI Yichi, XIANG Yupeng, et al. Dynamic stochastic optimal power flow of wind integrated power system considering temporal and spatial correlation of wind speed [J]. Proceedings of the CSEE. Vol. 35 (2015) No. 17, p. 4308-4317.

[2]. Mohammadi M, Shayegani A, Adaminejad H. A new approach of point estimate method for probabilistic load flow [J]. International Journal of Electrical Power \& Energy Systems. Vol. 51(2013), p.54-60.

[3]. Yu H, Rosehart B. Probabilistic power flow considering wind speed correlation of wind farms[C]. 17th Power Systems Computation Conference. Sweden, 2011, p. 1-7.

[4]. TANG Yi, WANG Qi, CHEN Ning, et al. A dispatching method of active power in wind farm clusters considering probability distribution of forecasting errors $[\mathrm{J}]$. Proceedings of the CSEE. Vol. 33 (2013) No. 25, p.27-32+7.

[5]. TANG Lei, SHEN Chen, ZHANG Xuemin. Impact of large-scale wind power centralized integration on transient angle stability of power systems-part I: theoretical foundation [J]. Proceedings of the CSEE. Vol. 35 (2015) No. 15, p.3832-3842.

[6]. LI Jinghua, ZUO Junjun, WANG Sai. Analysis and assessment of operation risk for power system with large-scale wind power integration [J]. Power System Technology. Vol. 40 (2016) No. 11, p.3503-3513. 
[7]. CHEN Huifen, QIAO Ying, MIN Yong, et al. Study on coordinated control strategy of dynamic and static reactive compensation in wind farm [J]. Power System Technology. Vol. 37 (2013) No. 1, p.248-254.

[8]. LI Ran, TANG Fan, LIU Yingpei, et al. A new scheme of reactive power compensation and voltage control for DFIG based wind farm [J]. Proceedings of the CSEE. Vol. 32 (2012) No. 19, p.16-23+180.

[9]. MA Rui, WANG Keyi, WU Gang. A novel reactive power compensation configuration of wind farms on inhibiting DFIG fleet off-grid [J]. Electric Power Construction. Vol. 36 (2015) No. 5, p.14-19.

[10]. XU Chang, YANG Jianchuan, LI Chenqi, et al. Optimization of wind farm layout in complex terrain [J]. Proceedings of the CSEE. Vol. 33 (2013) No. 31, p.58-64+7.

[11]. Liu Gengrui, Zhang Zhiguo. Design and optimize the design of wind farm access system [J]. Inner Mongolia Petrochemical Industry. (2012) No. 12, p.103-104.

[12]. Yuan Jingwei. Analysis of wind farm's connection modes, grid connection and operation modes [J]. Electricity and Energy. Vol. 33 (2012) No. 1, p.58-64+7.

[13]. WANG Yihong, HUANG Bin, SHEN Hong et al. Transmission capacity of grid-connecting channel for the second phase of $3 \mathrm{GW}$ jiuquan wind power base project and configuration of its reactive power compensation equipments [J]. Power System Technology. Vol. 37 (2013) No. 5, p.1440-1446. 